\title{
8
}
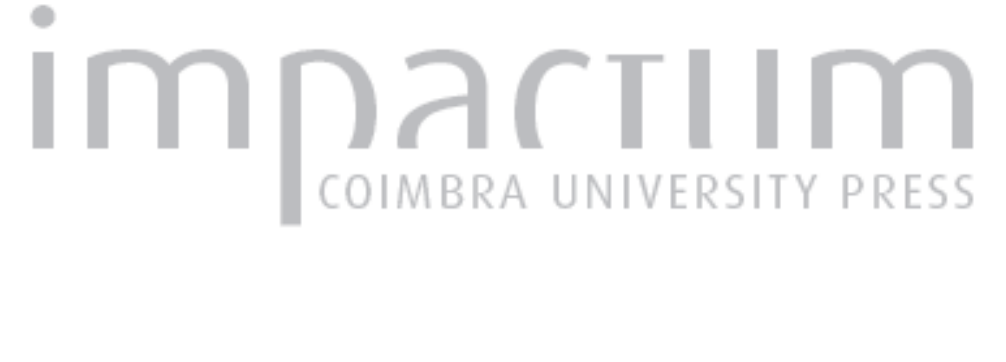

\section{Juvarra: cenografia e urbanística para uma capital do lluminismo}

\section{Autor(es): Rossa, Walter}

Publicado por: Imprensa da Universidade de Coimbra

URL persistente:

URl:http://hdl.handle.net/10316.2/44980

DOI:

DOI:https://doi.org/10.14195/0870-8584_12_17

Accessed : $\quad$ 26-Apr-2023 13:03:53

A navegação consulta e descarregamento dos títulos inseridos nas Bibliotecas Digitais UC Digitalis, UC Pombalina e UC Impactum, pressupõem a aceitação plena e sem reservas dos Termos e Condições de Uso destas Bibliotecas Digitais, disponíveis em https://digitalis.uc.pt/pt-pt/termos.

Conforme exposto nos referidos Termos e Condições de Uso, o descarregamento de títulos de acesso restrito requer uma licença válida de autorização devendo o utilizador aceder ao(s) documento(s) a partir de um endereço de IP da instituição detentora da supramencionada licença.

Ao utilizador é apenas permitido o descarregamento para uso pessoal, pelo que o emprego do(s) título(s) descarregado(s) para outro fim, designadamente comercial, carece de autorização do respetivo autor ou editor da obra.

Na medida em que todas as obras da UC Digitalis se encontram protegidas pelo Código do Direito de Autor e Direitos Conexos e demais legislação aplicável, toda a cópia, parcial ou total, deste documento, nos casos em que é legalmente admitida, deverá conter ou fazer-se acompanhar por este aviso.

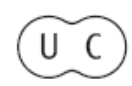




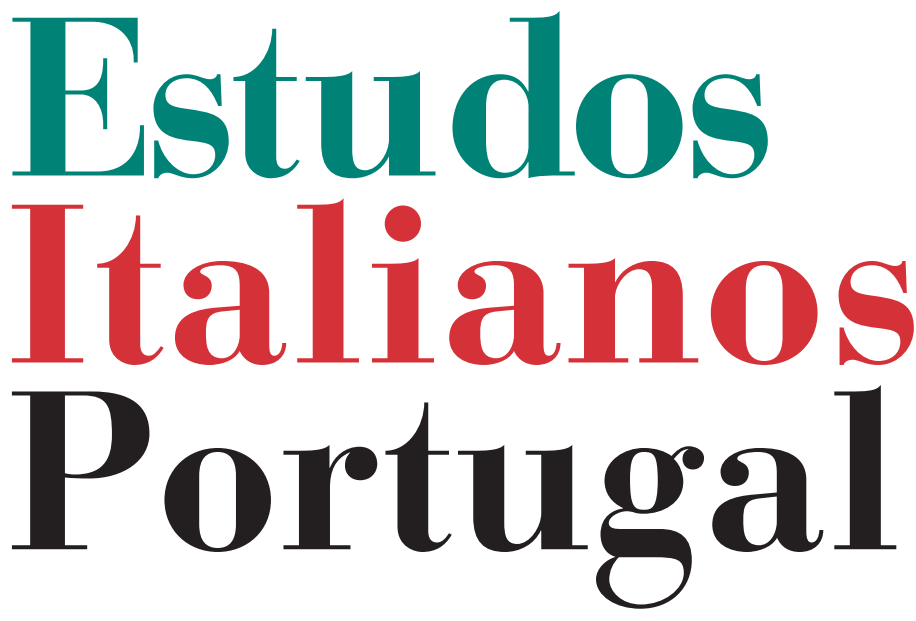

Instituto

Italiano

de Cultura

de Lisboa

Nova Série

No 12

2017 


\title{
JUVARRA: CENOGRAFIA E URBANÍSTICA PARA UMA CAPITAL DO ILUMINISMO
}

\author{
WALTER RossA*
}

Filippo JuvarRa (1678-1736) nasceu em Messina numa família de origem basca de ourives e gravadores, que lhe proporcionou formação de base e as primeiras encomendas artísticas. Autodidata até ir para Roma em 1704 (um ano depois de ter sido ordenado sacerdote), os seus dotes e empenho catalisaram uma rápida ascensão no meio profissional romano, do que são prova as integrações na oficina de Carlo Fontana (1704), na Accademia di San Luca (1706), na corte do cardeal Pietro Ottoboni (1708) e na Accademia dell'Arcadia (1712). Em 1714 entrou para o serviço da casa de Saboia de quem, no fundo, passou a ser súbdito pela disposição do Tratado de Utrecht (1713), que determinou a passagem da Sicília para o domínio piemontês, cedo revertido (1718). Aí trabalhou em arquitetura efémera, o que acabou por se refletir na sua produção arquitetónica. Um extraordinário talento artístico e uma invulgar capacidade de trabalho são testemunhados pela profusão e qualidade dos seus pensieri, desenhos de uma impressionante fluidez criativa e traço inconfundível, já numa linha que atingiria o auge com Giovanni Battista Pirannesi (1720-1778).

\footnotetext{
*Walter Rossa é arquiteto, investigador do Centro de Estudos Sociais e professor catedrático do Departamento de Arquitetura da Universidade de Coimbra. Dedica-se à investigação sobre urbanismo e paisagem urbana, com especial enfoque na sua dimensão patrimonial, ou seja, na perspetiva do seu desenvolvimento sustentável. wrossa@uc.pt
} 
A inserção de Juvarra no que a historiografia da arquitetura mais convencional, por vezes pejorativamente, intitula de barroco tardio, o facto de parte da sua criação ter sido para o efémero, bem como a obra que perdurou se concentrar essencialmente em Turim ${ }^{1}$, foram confinando a medida justa de reconhecimento da sua extraordinária relevância na História da Arquitetura ao círculo, sempre restrito, de especialistas da Idade Clássica. Só assim se compreende porque é que, com estudos dirigidos à sua vida e obra desde finais do século XIX,

La bibliografia su Filippo Juvarra annovera a tutt'oggi circa centoconquanta titoli raccolti soprattuto a partire dagli anni settanta del XX secolo e suddivisi tra monografie, cataloghi di mostre, saggi tematici, studi specifici su edifici o programmi decorativi, su raccolte di grafica, progetti scenografici e achitetture effimere, sulla produzione orafa, le incisioni e le opere realizzate a fini didattici. ${ }^{2}$

E continua a crescer, até porque prossegue a identificação dos seus pensieri e de novos documentos sobre a sua vida e obra.

Não poderia ser meu propósito proporcionar aqui uma visão panorâmica sobre tudo isso, pois o contexto é o do papel desempenhado por arquitetos italianos em Portugal. Mesmo nesse âmbito Juvarra é um caso especial, difícil e até paradoxal, pois foi o que menos tempo esteve no país, o que maior reconhecimento e honrarias régias teve e o que não realizou em Portugal obra de autoria autónoma reconhecível.

\footnotetext{
${ }^{1}$ Pesem embora a riqueza, monumentalidade e qualidade urbanas e arquitetónicas da capital do Piemonte, não se pode dizer que é popular entre os destinos turísticos ou que tenha merecido uma divulgação e/ou reconhecimento equiparáveis aos de muitas outras cidades italianas ricas em itens da Idade Clássica.

${ }^{2}$ P. Cornaglia et al. (ed.), Filippo Juvarra, 1678-1736. Architetto dei Savoia, architetto in Europa, Roma, Campisano, 2014, vol. 2, p. 11. Será o conjunto mais recente, completo e diversificado de textos sobre a sua obra.
} 
Nada disso é comum a qualquer um dos colegas itálicos que na sua época, mesmo alargada da Restauração à Revolução Liberal, trabalharam em Portugal, o que torna claro porque é que, apesar de desde sempre se saber desse breve episódio da sua carreira, tenha tardado o interesse por ele e pelo facto de ser da razão das suas viagens fora de Itália. Os trabalhos que lhe têm sido dedicados oscilam entre o seu estudo em função da vida e obra do arquiteto e o seu contributo para a cultura arquitetónica portuguesa, o que, pelo menos para já, apenas tem interessado à historiografia portuguesa. E este último o enfoque que anima este texto.

\section{Os 5 PENSIERI}

A análise da missão de Filippo Juvarra a Portugal no primeiro semestre de 1719 passa, obrigatoriamente, por dois requisitos. Primeiro pelo domínio das fontes que se lhe referem que, apesar de diversas e dispersas, estão identificadas e publicadas, surgindo de vez em quando um elemento novo. Depois um conhecimento detalhado das diversas caraterísticas do contexto coevo (geográfico, urbanístico, político, religioso, diplomático) onde ocorreu. É esta uma matéria em que um menor investimento dos especialistas em Juvarra tem levado a identificaçōes e interpretaçōes erradas, que depois se reproduzem, apesar de a historiografia portuguesa dedicada ao assunto, mais informada até pelo domínio da língua, não deixar de as corrigir. Para este requisito é excessivamente vasta a bibliografia e fontes a invocar, podendo recorrer-se a sínteses disponíveis sobre as suas diversas vertentes. Já no que diz respeito ao primeiro requisito, nada de Juvarra foi até agora identificado em acervos portugueses, e mesmo outros tipos de dados primários que se referem à sua missão a Portugal têm maioritariamente vindo a ser resgatados em arquivos e fontes estrangeiros. Como em todas as situações semelhantes, é algo que tem vindo a ser justificado com as 
destruições e perdas decorrentes da catástrofe lisboeta de 1 de novembro de 1755 .

Entre essas fontes impõe-se, desde logo, a sua biografia anónima, provavelmente de autoria de seu irmão Francesco (ou até do próprio) não sob a forma de um diário, mas como algo escrito anos depois ${ }^{3}$, o que é um dado relevante para a sua leitura crítica. Por sua vez, na década de 1970 uma das primeiras estudiosas de Juvarra, Aurora Scotti ${ }^{4}$, apontou 4 desenhos dos 4 álbuns de pensieri de Juvarra do Museo Civico di Torino como provindo da sua estadia em Portugal, sendo que mais tarde ficou claro que um deles não poderia integrar o conjunto 5 . O facto de o Palácio Real e Convento de Mafra ter sido a única obra, erguida por essa altura no país com escala correspondente à desses desenhos, fez com que a historiografia italiana os relacionasse diretamente com ela, equívoco ainda não totalmente esvanecido, mesmo depois de, pelo menos desde a década de $1990^{6}$, estar cabalmente

${ }^{3}$ Vita del cavaliere don Filippo Juvarra. Abate di Selve e Primo Architetto di S. M. di Sardegna. Publicada várias vezes, utilizei a transcrição inicial de Adamo Rossi de 1874 e republicada em Vittorio Viale (org.), Mostra di Filippo Juvarra architetto e scenografo, Messina, Istituto di Disegno, Universitá degli Studi di Messina, 1966.

${ }^{4}$ Aurora Scotti, "L'Accademia degli arcadi in Roma e i suoi rapporti con la cultura portoghese nel primo ventennio del 1700", Bracara Augusta, 63-75, a. 27, t. 1, 1973, pp. 115-130; id., "L'attività di Filippo Juvarra a Lisbona alla luce delle più recenti interpretazione critiche della sua architettura con una appendice sui rapporti Roma-Lisbona", Colóquio. Artes, 2. ${ }^{a}$ s., 28, 1976, pp. 51-63.

${ }^{5}$ Musei Civico di Torino [MCT]: Inv. 1859/DS, vol. 1, fl. 97, dis. 157; Inv. 1860/ DS, vol. 1, fl. 98, dis. 158; Inv. 1706/DS, vol. 1, fl. 4, dis. 7.

${ }^{6}$ Walter Rossa, Além da Baixa. Indícios de planeamento urbano na Lisboa setecentista, Lisboa, Instituto Português do Património Arquitectónico, 1998 [tese de mestrado de 1991]; Gianfranco Gritella, Juvarra. L'architettura, Modena, Franco Cosimo Panini, vol. 1, 1992, pp. 462-469. Ver ainda uma atualização do primeiro em Walter Rossa, "Lisbon's waterfront image as allegory of baroque urban aesthetic", Henry A. Millon (ed.), Symposium Circa 1700. Architecture in Europe and the Americas [2000], Washington, National Gallery of Art [Studies in the History of Art, 66], 2005, pp. 160-185 (versão port., Walter Rossa, A urbe e o traço. Uma década de estudos sobre o urbanismo português, Coimbra, Almedina, 2002, pp. 87-121). 
estabelecida a sua relação com um projeto ainda bem mais grandioso de D. João V (r.1707-1750), a renovação do complexo palatino de Lisboa. É também de então a identificação de um outro pensiero como relativo a Lisboa, no caso um farol monumental a erguer na margem do Tejo em Santos ${ }^{7}$. $\mathrm{O}$ quinto e, por enquanto, o último dos desenhos de Juvarra identificados como sendo do episódio de Lisboa, foi também primeiro "unequivocably" relacionado com $\mathrm{Mafra}^{8}$, sendo no mesmo ano devidamente ligado ao processo de Lisboa'. São estas seis - a biografia e os cinco desenhos - as fontes diretas, de Juvarra, da sua missão a Portugal ${ }^{10}$, o que dada a sua importância não deixa de ser paradoxal. Há, contudo, um outro pequeno núcleo de um episódio antecedente que, aliás, permite introduzir o relato da preparação dessa missão.

${ }^{7}$ Biblioteca Nazionale di Torino [BNT], Ris. 59.1, fls. 22-23. Textos de Walter Rossa na n. anterior.

${ }^{8}$ BNT, Ris. 59,6, fl. 31 bisv. Tommaso Manfredi, "Roma communis patria: Juvarra and the British", Roma Britannica. Art Patronage and Cultural Exchange in Eighteenth Century Rome, Roma, British School, 2011, p. 209.

${ }^{9}$ Giuseppina Raggi, "Filippo Juvarra a Lisbona: due progetti per un teatro regio e una complessa questione musicale", Filippo Juvarra, 1678-1736. Architetto dei Savoia, architetto in Europa, vol. 2, pp. 209-228. Apesar de a edição ser de 2014, o colóquio de que resultou o livro decorreu em novembro de 2011, versão port. "A idealização de dois projetos para o teatro régio e um novo desenho do arquitecto Filippo Juvarra para a corte portuguesa", Revista de História da Arte, 11, 2014, pp. 137-151.

${ }^{10}$ Giuseppina Raggi (ver n. anterior) trabalhou cinco desenhos que serão cópias de originais de Juvarra para um teatro a construir no Paço da Ribeira em Lisboa. Seriam, contudo, posteriores (1721?-1723?) à sua estadia em Lisboa, embora dela decorrentes. Por outro lado, recentemente surgiu uma proposta de mais três pensieri da sua missão em Lisboa em Tommaso Manfredi, "Prospettive dal Tejo. La nuova Lisbona di Giovanni V in tre vedute di Filippo Juvarra”, ArcHistoR 7, 2017, http://pkp.unirc.it/ojs/ index.php/archistor (consultado a 30-05-2017). Todavia as bases para a interpretação do autor estão erradas (ver n. 36) e a realidade física do território de Lisboa, hoje e na época, facilmente desacreditam a hipótese colocada. Aliás, um dos desenhos tem uma proposta de identificação bastante mais plausível em Vera Comoli Mandracci, "La dimensione urbanistica di Juvarra per l'idea delle città-capitali”, Vera Comoli Mandraci; Andreina Griseri (ed.), Filippo Juvarra. Architetto delle Capitali da Torino a Madrid 1714-1736, Torino, Fabbri, 1995, p. 54. 


\section{DEFINIÇÃO DO PROGRAMA E RECRUTAMENTO}

Como já vimos, o convite que levou Juvarra a Portugal tinha como finalidade a sua definição do projeto da renovação do complexo palatino de Lisboa. Desde a inclusão por D. Manuel I, nos inícios de Quinhentos, de uma residência régia no complexo, então em formação, da Ribeira das Naus, que as obras não cessaram, o que revela a permanente insatisfação com as condições de um palácio que, sendo a referência icónica da monarquia portuguesa, nunca correspondeu ao que seria de esperar no caput mundi que a cidade foi durante as décadas seguintes. A estruturação do Paço da Ribeira ${ }^{11}$, designação com que se celebrizou, partiu do que veio a ser a Praça da Patriarcal no extremo poente da Rua Nova (a versão pré-Terramoto de 1755 da atual Praça do Município), mas foi a sua extensão sobre o aterro em formação sobre o rio que lhe concedeu imagem, em especial quando D. Filipe II ordenou a substituição do remate sul com o torreão que inspirou os dois atuais da Praça do Comércio. Essa ala do paço e o conjunto que, de poente para nascente, se adoçou à muralha medieval, consubstanciaram o logradouro do poder celebrizado sob a designação Terreiro do Paço, que mais de dois séculos e meio depois da restauração pós-Terramoto de 1755 continua a ensombrar a (re)designação do locus então estabelecida. Assim se fixara a principal imagem de Lisboa anterior a essa catástrofe $\mathrm{e}^{12}$.

${ }^{11}$ É um assunto acerca do qual existe uma vastíssima bibliografia. Para uma visão global ver Nuno Senos, O Paço da Ribeira 1501-1581, Lisboa, Editorial Notícias, 2002; Miguel Figueira de Faria (ed.), Do Terreiro do Paço à Praça do Comércio. História de um espaço urbano, Lisboa, Imprensa Nacional - Casa da Moeda, 2012.

${ }^{12}$ Walter Rossa, "Lisboa: da busca de imagem de capital", Rossio. Estudos de Lisboa, 5, 2015, pp. 28-43; id., "Lisboa Quinhentista, o terreiro e o paço: prenúncios de uma afirmação da capitalidade”, D. João III e o Império. Actas do Congresso Internacional Comemorativo do Nascimento de D. João III, Lisboa, CHAM [Universidade Nova de Lisboa], CEPCEP [Universidade Católica Portuguesa], 2004, pp. 947-967, reed. id., Fomos condenados à cidade: uma década de estudos sobre património urbanístico, Coimbra, Imprensa da Universidade, 2015, pp. 287-312. 
Foi no espaço que inicialmente partilhava com a Casa da Índia e outras dependências centrais às operações náuticas e comerciais da expansão portuguesa que o Paço da Ribeira se foi desenvolvendo, sem que algo disso tivesse resultado de um plano integrado. Houve, contudo, momentos em que um plano global foi esboçado.

Quando em 1679 se discutiram os preparativos para a receção e acolhimento do Duque de Saboia, Vittorio Amedeo II (d.1675-1730), como consorte da herdeira do trono português Isabel Luísa Josefa de Bragança, as dependências do Paço da Ribeira estavam em muito mau estado. Em pleno século de definição urbanística das grandes capitais europeias $^{13}$ tornou-se evidente a necessidade de atuar, colocando-se duas hipóteses, ambas de ensanche do paço e não da sua reabilitação ou renovação ${ }^{14}$. Uma consistia na duplicação da ala poente do Terreiro do Paço, incluindo o torreão, em espelho para nascente da ala sul, ou seja, no sítio da Alfândega Nova erguida no reinado de Manuel I. Como é óbvio foi o que mais tarde acabou por acontecer, em simultâneo com uma extensão sobre o rio, na execução do plano de reconstrução da cidade pós-Terramoto, o Plano de $1758^{15}$. Outra fazendo uma ala de ligação ribeirinha entre os paços da Ribeira e o Corte-Real, situado a poente

\footnotetext{
${ }^{13}$ Alexandre Le Maître, La métropolitée, ou de l'établissement des villes capitales, de leur utilité passive et active, Amesterdão, B. Boekholt, pour J. Van Gorp, 1682; Walter Rossa, "Capitalidades à portuguesa: território de origem", Fomos condenados à cidade. Uma década de estudos sobre património urbanístico, pp. 147-165.

${ }_{14}$ Miguel Soromenho, "O Paço da Ribeira à medida da Corte: de Filipe I a D. Pedro II”, Do Terreiro do Paço à Praça do Comércio. História de um espaço urbano, pp. 37-71; Walter Rossa, "L'anello mancante: Juvarra sogno e realtà di un'urbanistica delle capitali nella Lisbona settecentesca", Filippo Juvarra, 1678-1736. Architetto dei Savoia, architetto in Europa, vol. 2, pp. 183-196, versão port. id., Fomos condenados à cidade: uma década de estudos sobre património urbanistico, pp. 313-336.

${ }^{15}$ Walter Rossa, "No 1. ${ }^{\circ}$ plano", Ana Tostōes; Walter Rossa (coord.), Lisboa 1758. O plano da Baixa hoje, Lisboa, Câmara Municipal de Lisboa, 2008, pp. 24-81.
} 
também sobre o rio, que fora integrado nos bens da Coroa. A falta de dinheiro, implicaçôes como a mudança da Ribeira das Naus e da Alfândega, mas essencialmente o malogro do projeto de aliança matrimonial dois anos depois, motivaram o seu abandono, ou melhor, suspensão, pois foi para concretizar este plano que, 40 anos depois, Juvarra foi chamado a Lisboa.

É, de facto, num contexto diverso que na década de 1710 o jovem D. João $\mathrm{V}$ avançou para uma reforma da sua capital que fizesse jus à dimensão do seu império. Portugal saíra do ciclo recessivo em que mergulhara com a União Ibérica e o processo de restauração da independência (1580-1668). Nisso teve um papel determinante a focagem do império colonial sobre o Brasil, que havia pouco começara a dar resultados materiais com a descoberta de significativas reservas auríferas e diamantíferas. Por outro lado, e segundo uma complexa teia de procedimentos, a diplomacia lograra o reconhecimento da soberania portuguesa sobre uma significativa maioria das posições coloniais anteriores à União Ibérica, e a recente (1708) aliança matrimonial com a Casa da Áustria não só consolidara o papel de Portugal na Europa, como trouxera para Lisboa uma renovada atitude cosmopolita, omnipresente em muitas açôes, algumas referidas neste texto ${ }^{16}$.

Concorrendo com tudo isso, desenvolvia-se o processo de reconstituição e fortalecimento do Padroado Português do Oriente, ou seja e de forma excessivamente simplificada, da prorrogativa que desde 1456 fora sendo concedida aos monarcas da Dinastia de Avis pelo Vaticano, de administração direta dos assuntos relativos ao catolicismo nos territórios

${ }^{16}$ Em especial em Giuseppina Raggi, "Filippo Juvarra in Portogallo: documenti inediti per i progetti di Lisbona e Mafra”, ArcHistoR, 7, 2017, http://pkp.unirc.it/ojs/ index.php/archistor (consultado a 30-05-2017), tem vindo a chamar a atenção para o papel que a rainha desempenhou diretamente nesse processo. 
revelados à Europa pela expansão portuguesa ${ }^{17}$. Na prática acabou por colocar os reis portugueses no topo de uma hierarquia religiosa com (potencialmente) mais súbditos diretos que o próprio papa. É uma temática com tanto de complexo, quanto de crucial, para a compreensão do processo pelo qual Juvarra foi convidado a atuar em Lisboa. A insinuação de secessão de uma igreja portuguesa foi frequente, situação que esteve ao rubro entre 1728 e 1732, o período de corte de relações diplomáticas entre Portugal e a Santa Sé.

D. João V tinha de convencer a Santa Sé e, desde Sisto V, Roma era, urbanisticamente, o caso de capital por excelência, ou seja, o modelo a emular. Foi com esse duplo propósito que nomeou (1707) e enviou (1712) para Roma como embaixador especial Rodrigo de Sá Almeida e Meneses (1676-1733), marquês de Fontes e, depois, de Abrantes ${ }^{18}$. O processo foi tão longo quanto conhecido nas suas diferentes vertentes, designadamente na ação mecenática desenvolvida em Roma ao mais alto nível em nome do monarca português - cujo clímax foi a entrada oficial em 8 de julho de $1716^{19}$ - e no fluxo artístico Roma-Lisboa que acabou por levar Juvarra a Lisboa. Fluxo que fez com que no Paço da Ribeira se fosse

${ }^{17}$ António da Silva Rêgo, O padroado português do Oriente, Lisboa, Agência Geral das Colónias, 1940; Charles R. Boxer, O império marítimo português 1415-1826, Lisboa, Ediçôes 70, [1969] 1992, cap. X; Eduardo Brasão, D. João Ve a Santa Sé. As relaçôes diplomáticas de Portugal com o governo pontificio de 1706 a 1750, Coimbra, Universidade de Coimbra, 1937; id., Subsídios para a história do patriarcado de Lisboa 1716-1740, Porto, Livraria Civilização, 1942; id., Relaçôes diplomáticas de Portugal com a Santa Sé, Lisboa, Academia Internacional da Cultura Portuguesa, 1973; id., Relaçôes externas de Portugal. Reinado de D. João V, Porto, Civilização, 1938.

${ }^{18}$ De Bellebat, Relation du voyage de Monseigneur André de Mello de Castro a la Cour de Rome, en qualité de Envoye Extraordinaire, Paris, 1709. Em Eduardo Brasão, D. João Ve a Santa Sé, estão publicadas as instruçóes do rei ao marquês de Fontes para a sua missão em Roma.

${ }^{19}$ Angela Delaforce, Art and Patronage in Eighteenth-Century Portugal, London, Cambridge University Press, 2002; Gabriele Borghini; Sandra Vasco Rocca (ed.), Giovanni $V$ di Portogallo (1707-1750) e la cultura romana del suo tempo, Roma, Àrgos, 1995. 
constituindo ao longo de todo o reinado uma espécie de museu da arquitetura de Roma com maquetas (algumas à escala natural), pinturas, desenhos, levantamentos de edifícios, esculturas, altares e outros elementos expostos nos seus salóes ${ }^{20}$. Em termos artísticos o ponto focal em Roma foi a oficina de Carlo Fontana, não sendo por acaso que parte significativa dos arquitetos e artistas de Roma que então tiveram relação com Portugal (Ludovice, Mattei, Canevari e o próprio Juvarra) passou antes pelos ensinamentos daquele mestre, que já trabalhava para a Coroa portuguesa desde o reinado anterior e pelos serviços prestados fora agraciado com a Ordem Militar de Cristo ${ }^{21}$. Com a sua morte em 1714 seria entre os seus discípulos que, inevitavelmente, o embaixador procuraria arquiteto para o plano palatino de Lisboa ${ }^{22}$.

Era de facto essa uma das principais incumbências do marquês de Fontes em Roma. Tornara-se necessário quem lhe desse a forma arquitetónica ${ }^{23}$ que alavancasse a instalação de

${ }^{20}$ Ayres de Carvalho, D. João Ve a arte do seu tempo, Lisboa, ed. autor. 2 vols., 1962; Angela Delaforce, "Lisbon, 'This New Rome': Dom João V of Portugal and Relations between Rome and Lisbon", Jay Levenson (ed.), The Age of the Baroque in Portugal, Washington, National Gallery of Art, 1993 [catálogo], p. 52.

${ }^{21}$ Fontana foi o autor da decoração e do catafalco armados em setembro de 1707 na Igreja de Santo António dos Portugueses em Roma pela morte de Pedro II. A iconografia revela o quanto já se apostava na recuperação do esplendor imperial português e do seu Padroado. Conhecemo-la por descrição e através de um desenho de Juvarra (BNUT, 59/4, fl. 104), que terá, pois, trabalhado no projeto. Tem como título "Per il funerale del Ré di Portogallo, Piero II". É a primeira conexão conhecida entre Juvarra e Portugal.

${ }^{22}$ Como ilustração para esse ambiente de sucessão do mestre é sempre referido o episódio do concurso para o projeto da nova sacristia do São Pedro lançado em 1715 por Clemente XI, no qual participaram, precisamente, Mattei, Canevari e Juvarra. Sobre o tema ver, entre muitos outros, Hellmut Hager, "The precedents of Clement XI's competition of 1715", Henry A. Millon (ed.), The Triumph of the Baroque. Architecture in Europe 1600-1750, New York, Rizzoli International Publications, 1999 [catálogo], pp. 568-569.

${ }^{23}$ Esta questão foi também desenvolvida noutros domínios artísticos, designadamente na música. Por exemplo, Domenico Scarlatti e um seu grupo de executantes chegou a Lisboa semanas depois de Juvarra ter partido. 
imagem da qual emergisse uma "nova Roma"24. Esta era uma ideia corrente, pelo menos no quotidiano da corte, pois segundo formas diversas surge em alguns documentos. Muito expressiva é, por exemplo e também pela data, a expressão do 11. ${ }^{\circ}$ conde de Redondo numa carta ao rei de 5 de novembro de 1716 manifestando a sua opinião em "quam conveniente seria, se fosse possivel, fazer-se nessa Corte a obra, $\mathrm{q}$ na de Roma, com tanto applauso executou Domiciano" 25 . Importa registar que essa carta nos dá prova de dois assuntos relevantes: que tinha sido realizado um levantamento geral da cidade (instrumento básico para qualquer ação de planeamento integrado); do pedido de divisão ao papa (que o aprovaria dois dias depois) de Lisboa em duas, Ocidental e Oriental, sendo a divisão pelo Terreiro do Paço. Com isso a capela do Paço da Ribeira poderia ser erguida à dignidade de catedral metropolitana e receber um conjunto de distinções raras dentro do universo católico (p. e. dignidade patriarcal e tiara para o titular), pelas quais os diplomatas portugueses lutariam com sucesso a seguir. Assim se guindaria o titular português para um nível próximo do próprio papa. Se perspetivado dessa forma, o projeto religioso de $\mathrm{D}$. João $\mathrm{V}$ não surge como excessivamente pio, mas como essencialmente político.

$\mathrm{O}$ marquês de Fontes, que além de cultura artística tinha alguns dotes de desenho, buscava (inverno de 1716-1717) por entre o grupo de Fontana estabelecer as bases do projeto de arquitetura. São duas as propostas enviadas para apreciação do rei de que temos notícia, uma de Tomazo Mattei (1654-1726), outra de Filipo Juvarra. Da primeira sabe-se apenas, por carta do rei, que não terá agradado a D. João V,

${ }^{24}$ A expressão surge escrita mais tarde em Fernando António da Costa de Barboza, Elogio funebre do Padre João Baptista Carbone da Companhia de Jesus, Lisboa, 1751, p. 15.

${ }^{25}$ Biblioteca da Ajuda, 54-XI-38(2). Publicada em Walter Rossa, Além da Baixa. Indícios de planeamento urbano na Lisboa setecentista, pp. 160-161. 
que diz ao seu embaixador para regressar, pois melhor será discutir o projeto pessoalmente ${ }^{26}$. Da segunda sabe-se que foi sintetizada num quadro a óleo pintado por Gaspar van Wittel (1653-1736), pai do famoso arquiteto Luigi Vanvitelli (1700-1773). O episódio está relatado de forma breve na biografia anónima de Juvarra e na listagem de Pascoli ${ }^{27} \mathrm{e}$ está confirmado por Vieira Lusitano (1699-1783), que o terá testemunhado pois estagiava em Roma, levado pelo embaixador $^{28}$.

E assim chegamos ao outro pequeno conjunto de desenhos diretamente relacionados com a ação de Juvarra em Lisboa, desta vez integrados na coleção vanviteliana de Ca$\operatorname{serta}^{29}$. É inequívoco que terão surgido durante a elaboração da referida pintura e que, independentemente da autoria

${ }^{26}$ Cópia da Carta $q$ foi ao Marq.s de Fontes no Corr. ${ }^{\circ}$ de 22 de Junho, Biblioteca Nacional, Lisboa, Col. Pombalina, cod. 157, fls. 214-215.

${ }^{27}$ Lione Pascoli, Vite de' pittori, scultori ed architetti viventi: dai manoscritti 1383 e 1743 della Biblioteca comunale Augusta di Perugia, Perugia, Canova, Treviso Lib. Ed., 1981, pp. 11, 12, 282. Os dados de Pascoli são essencialmente os da biografia anónima, pois foi no seu espólio que em 1874 Adamo Rossi encontrou o respetivo manuscrito.

${ }^{28}$ Francisco Vieira de Matos (Vieira Lusitano), O insigne pintor e leal esposo, Lisboa, 1780.

${ }^{29}$ Palazzo Reale di Caserta, inv. n. ${ }^{\circ} 1787$ r.v e 1583 . Estão listados na coleção e Luigi Vanvitelli por Cesare de Seta, Luigi Vanvitelli, Napoli, Electa, 1998, p. 179; e Jörg Garms (org.), Disegni di Luigi Vanvitelli nelle collezioni pubbliche di Napoli e Caserta, Napoli, Palazzo Reale, 1974 [catálogo]. Foram, porém, publicados e comentados por: Walter Vitzthum, "Gaspar van Wittel e Filippo Juvara”, Arte Illustrata, maio-junho 1971, pp. 5-9; Aurora Scotti, "L'attività di Filippo Juvarra a Lisbona alla luce delle più recenti interpretazione critiche della sua architettura con una appendice sui rapporti Roma-Lisbona"; Jörg Garms, "Luigi Vanvitelli (1700-1773). Studi per vedute di Lisbona”, Sandra Vasco Rocca; Gabriele Borghini (ed.), Giovanni V di Portogallo (17071750) e la cultura romana del suo tempo, Roma, Àrgos, 1995 [catálogo da exposição], pp. 54-55. Enquanto Garms defende que Luigi Vanvitelli terá participado no processo como assistente do pai, Vitzthum afirma que foram "taken from natural", pelo que nem Juvarra nem nenhum dos Vanvitelli podem ser seus autores. 
(que é de mãos diversas), a realidade que retratam só pode ter sido inferida pelo marquês de Fontes e/ou pelo jovem Vieira Lusitano, os únicos que a conheciam. Aliás, o biógrafo de Juvarra diz claramente que, "e andato a far riverenza al signor ambasciatore, questi gli mostrò un modello di sua invenzione della chiesa patriarcale di Lisbona e del palazzo reale, ed ordinò a don Filippo che ne facesse un disegno in prospettiva con veduta del porto e di quella parte di città che si scopre da quel sito". Os desenhos representam edifícios urbanos facilmente reconhecíveis como arquitetura corrente lisboeta, mas se alguma dúvida persistisse, os caraterísticos Torreão da Ribeira e Palácio Corte Real dissipam-nas por completo. Curiosamente são dois exemplos muito claros da influência da arquitetura civil espanhola em Portugal durante a União Ibérica.

Em concreto nada mais se sabe acerca do óleo com a perspetiva de Juvarra inspirada no "modelo" da "invenzione" do embaixador. Sabe-se que este regressou a Lisboa em abril de 1718 e que no fim desse ano Juvarra, com licença do seu patrono piemontês, partiu para Lisboa onde chegou no final do mês, permanecendo até aos finais de julho. As boas relações, incluindo as duas tentativas, em apenas quatro décadas, de casamento de príncipes de Saboia com princesas da Casa de Bragança, decerto terão facilitado as coisas.

NOVO PARADIGMA PARA UMA CAPITAL

Os detalhes da estada de Juvarra em Lisboa têm vindo a ser apurados por diversos autores com base num já vasto manancial de fontes escritas. Além dos testemunhos dados na sua biografia anónima e pelo cronista João Baptista de Castro ${ }^{30}$,

\footnotetext{
${ }^{30}$ João Baptista de Castro, Mapa de Portugal antigo, e Moderno, Lisboa, 1762, vol. 3.
} 
são as cartas dos diplomatas estrangeiros acreditados em Portugal que têm fornecido as informações mais substanciais ${ }^{31}$. Já em 1717 o núncio informava o Vaticano que o projeto estava em discussão na corte de Lisboa ${ }^{32}$. O tom é o que desde então manteve, ou seja, denunciando alguma preocupação por se tratar do projeto de "una gran chiesa, e Palazzo Patriarcale, unito ad altro Regio di struttura all'uso di Roma"33, desígnio de emulação que, já se referiu, deveria correr publicamente. Veja-se como na biografia de Juvarra se lê tratar-se de "un disegno di tanta magnificenza e bellezza da promettere una fabbrica non puré seconda, ma uguale alla gran mole di S. Pietro, degna della grandeza di quel re" e ainda que o rei "ordinógli che facesse un disegno del palazzo reale, della cheisa patriarcale, del palazzo per il patriarca e della canonica, con questa ingiunzione che quella fabbrica dopo la rinomata gran mole di S. Pietro di Roma, tenesse il primo posto". Não seria coisa agradável de se saber em Roma, tal como que "L'Architetto ha fatto un sbozzo del dissegno della nova chiesa da fabricarsi, il quale hà piacciuto molto alla M.tà del Re, credendosi, che sia più bello di quello della Chiesa di S.

${ }^{31}$ Desde os trabalhos de Aurora Scotti já antes referenciados, que as cartas do núncio em Lisboa, monsenhor Bichi, do acervo do Archivio Segreto Vaticano [ASV], foram exaustivamente analisadas por múltiplos investigadores, estando assim os seu trechos publicados na bibliografia que tem vindo a ser citada. O mesmo sucede com as mais raras e menos interessantes cartas do Archivio di Stato di Torino [AST], escritas entre 1720 e 1722, por causa da tentativa de casamento entre o príncipe Carlo Emmanuele di Saboia e a irmã de D. João V, Francisca. Maiores novidades apresenta o conjunto recém compulsado em Giuseppina Raggi, "Filippo Juvarra in Portogallo: documenti inediti per i progetti architettonici di Lisbona e Mafra", do Haus-, Hofund Staatsarchiv (Viena) [HHSA], escritas pelo embaixador Giuseppe Zignoni a Leopoldo I, José I e Carlos VI. Aliás, nesse trabalho a autora faz uma excelente resenha relacional do todo dessas fontes, estabelecendo um novo patamar no que diz respeito às fontes documentais para o estudo do tema.

${ }^{32}$ ASV Portogallo, Seg. 74, fl. 44.

${ }_{33}$ Despacho de 14-02-1719, ASV Portogallo, seg. 75, fl. 26. A 2 de março relata que "havendone di già nelle mani I disegni" (ASV, Portogallo, Seg. 74, fl. 44). 
Pietro in Roma." ${ }^{34}$ E que no final da missão deixara "dele bellissime piante, e disegni magnificentissimi" ${ }^{35}$. São de facto muitos os excertos interessantes pela cor e ambiente que dão acerca da presença e trabalho de Juvarra em Lisboa. Contudo não cabem neste texto, pelo que me limito a referir o que de essencial deles se infere.

Juvarra foi recebido e instalado com grande aparato (p. e. carruagem de seis cavalos e casa luxuosa com vários criados), o que é revelador da expetativa e relevância dada pelo rei à sua presença e desempenho. Terá desde logo trabalhado no desenvolvimento do projeto delineado em Roma, ou seja, a reforma e ensanche radicais do Paço da Ribeira pela construção ao longo do rio, entre o Terreiro do Paço e o Paço Corte Real. Os desenhos de Caserta são suficientes para o perceber e o último dos pensieri, o quinto a ser identificado com Lisboa, que tem esse palácio em primeiro plano, é muito sugestivo $^{36}$. Porém a dúvida sobre as qualidades do local para o pretendido ter-se-á também colocado no início, pois mal Juvarra chegou, ele e o rei procuraram a implantação ideal durante jornadas de carruagem às voltas nos arredores e num barco no Tejo. Uma vez encontrada e apontada em desenho como alternativa, ambas foram debatidas por um conselho alargado de especialistas de diversas áreas, bem como de notáveis da corte. Ao que parece, o marquês de Fontes bateu-se ingloriamente pela solução inicial, enquanto Juvarra assistiu sem se pronunciar e os médicos obviamente invetivavam a Ribeira e enalteciam Buenos Aires.

${ }^{34}$ HHSA, Portugal 6, 6-2, c. 96.

${ }_{35}$ Despacho de 18-07-1719, ASV Portogallo, seg. 75, fl. 175.

${ }^{36}$ Em três textos Sandra Sansone exercitou três variantes muito sugestivas: Sandra Sansone, "Del Palazzo de' Cesari". L'attività di Filippo Juvarra per Dom João V di Portogallo, Tese de licenciatura apresentada ao IUAV, Venezia, 2010; "La collaborazione tra Filippo Juvarra e i Vanvitelli per il palazzo reale di Lisbona", Annali di Architettura, 24, 2012, pp 131-140; “' 'Del Palazzo de' Cesari'. Linea sul titolo dell'attività di Filippo Juvarra per D. João V di Portogallo”, Revista de História da Arte, 11, 2014, pp. 123-135. 
A nova localização tinha com ponto de referência a "Cruz de Buenos Aires", então na encruzilhada de uma área ampla e praticamente desprovida de construçóes, que descia em suave declive até terminar numa falésia sobre o rio, e era interior à Linha Fundamental de Fortificação que constituía o limite urbano da cidade ${ }^{37}$. Hoje podemos identificá-la como subindo desde as Necessidades sobre a Ribeira de Alcântara até Campo de Ourique, e daí descendo à Estrela, Lapa e, de novo sobre o rio, Santos. No centro persiste o topónimo central na Rua de Buenos Aires. Nesta nova implantação seria possível aumentar o programa e a ambição. A esse propósito, veja-se o que em 28 de março de 1719 oficiava o núncio para Roma: "Giardino e Zappada per animali silvestre, si è molto bello e salutifico, sopra la collina che domina la città e scopre l'entrata del mare sia li due castelli di San Giuliano e del Bugio, e tutta la Bayra fuori" ${ }^{\prime 3}$. Num documento dado a conhecer recentemente lê-se ainda: "l'ideate fabbriche di una Basilica con Palazzo Patriarcale, di un Palazzo Reggio, di una Casa di Campo reggia, di un Arsenale ed altri edifitij" 39 . Afinal acrescia ao paço e patriarcal uma tapada de caça e uma casa de campo.

Seriam para essa nova implantação os três pensieri primeiro identificados por Aurora Scotti ${ }^{40}$, devendo ser-lhes agregado o que representa a coluna-farol monumental a erguer no rio frente a todo o conjunto. Segundo a biografia anónima "La prima ordinazione che ricevette fu quella di un disegno

${ }^{37} \mathrm{Na}$ tese referida na n. anterior e em Sandra Sansone, "La reggia di João V di Portogallo: il projetto per Buenos Aires a Lisbona", Filippo Juvarra, 1678-1736. Architetto dei Savoia, architetto in Europa, vol. 2, pp. 197-208, a autora localiza tudo isto na atual colina da Ajuda, onde a seguir ao Terramoto foi construído o novo palácio. É, contudo, uma hipótese que contraria inúmeros dados cartográficos, documentais, topográficos e toponímicos e que, aliás, se baseia num mapa cuja correta interpretação confirma, uma vez mais, que Buenos Aires é no sítio aqui e desde sempre indicado.

${ }^{38}$ ASV Portogallo, seg. 75, fl. 63.

${ }^{39}$ HHSA, Portugal 6, 6-2, c. 132.

${ }^{40}$ Ver ns. 5, 6, 7. 
per il fanale del porto; per il quale avendo ideato una colonna sullo stile antico ad imitazione di quelle che si vedono in Roma, con l'arme del re in mezzo retta da due fame, ed in cima un gran fanale [...] per imitare le opere degli antichi imperatori”. Ao fundo vê-se a silhueta do Palácio da Ribeira. A análise desses quatro desenhos dispensa que se destaque o programa funcional a que procuram obedecer (palácio e patriarcal), ainda menos o programa retórico e os desígnios paisagístico, simbólico e de emulação romana.

A seleção de Juvarra para a tarefa teve, precisamente, em conta a sua abordagem cenográfica a todas as encomendas, o que é patente nas obras que realizou nas quais a implantação o permitia, como na Basílica da Superga e no Palácio de Rivoli, ou criando condiçóes para tal, como no Palácio de Stupinigi (todos na zona de Turim), para não referir as inúmeras que projetou ou sonhou. Cenografia que encontrava terreno próprio nas situações efémeras que também em Lisboa vão surgindo documentadas, com especial destaque para a festa do Corpo de Deus, para a qual de facto estabeleceu um novo paradigma. Não se esqueça, todavia, a dimensão estrutural, urbanística, da ação de Juvarra, bem patente no ensanche que programou em Turim (1714) que, aliás, seria referido por Manuel da Maia (1678-1763) na sua Dissertação (novembro 1755 -abril de 1756 ) estratégica para a definição do plano de reconstrução de Lisboa após a catástrofe de $1755^{41}$.

O conhecimento do terreno, condição central para a resposta competente de qualquer arquiteto, era necessariamente, em Juvarra, um catalisador fulcral da sua criatividade artística. Por isso não se poderá duvidar do forte impacto que a magnífica relação da topografia de Lisboa com o Tejo lhe

${ }^{41}$ Walter Rossa, "No 10 Plano"; id., "Dissertação sobre a reforma na cultura do território do pombalismo", A. C. Araújo; J. L. Cardoso; N. G. Monteiro; J. V. Serrão; W. Rossa, O Terramoto de 1755. Impactos históricos. Lisboa, Livros Horizonte, 2007, pp. 379-393 (também publicado em id., Fomos condenados à cidade. Uma década de estudos sobre património urbanístico, pp. 363-388). 
tenha causado, do que resulta óbvio ter sido ele o catalisador da mudança do foco do projeto palatino de $\mathrm{D}$. João $\mathrm{V}$ da Ribeira para Buenos Aires. Além do projeto em si, que não se concretizou e não conhecemos, essa alteração constituiu uma rotura de fundo, estrutural na forma de pensar o futuro da cidade. Se, paradoxalmente, depois do seu retorno a Turim sem que o almejado regresso se concretizasse, o rei acabou por investir fortemente na renovação do Paço da Ribeira, a verdade é que ao longo do seu reinado muito se fez para estruturar a expansão para poente da cidade.

Desde logo com a corte de recreio catalisada entre a Junqueira e Pedrouços pela composição do Palácio de Belém (a concretização da Casa de Campo reggia. ${ }^{42}$ ), apoiada no Projecto do Cais Novo de Belém ao Cais de Santarém de Carlos Mardel (1695-1763) em $1733^{43}$, tal foi prefigurado na entrada régia de 12 de fevereiro de $1729^{44}$. Projeto que, aliás, previa a mudança da Ribeira das Naus para Alcântara. Depois com a construção, a partir de 1728, do Aqueduto das Águas Livres, claramente gizado para abastecer todo o setor ocidental da cidade ${ }^{45}$, o que então menos densidade populacional tinha. A verdade, porém, é que as tentativas para encontrar água em Buenos Aires haviam saído frustradas. Entre algumas outras ações anote-se ainda a construção

${ }^{42}$ Ib. n. 39. Esta hipótese surge melhor exposta em Giuseppina Raggi, "Filippo Juvarra in Portogallo: documenti inediti per i progetti di Lisbona e Mafra", que, como já antes foi anotado, aponta para um relevante papel da rainha no processo.

${ }^{43}$ Arquivo Histórico do Ministério das Obras Públicas (Lisboa), D27C. O levantamento que lhe serviu de base foi realizado seis anos antes: Planta Topographica da marinha de Lisboa Occidental, e Oriental, desde o Forte de S. Joseph de Ribamar té o Convento do Grilo feita no anno de 1727, Museu da Cidade (Lisboa), cota 1387.

${ }^{44}$ Manoel Coelho da Graça, Breve noticia das entradas que por mar, e terra fizeraó nesta Corte Suas Magestades com os Serenissimos Principes do Brazil, e Altezas que Deos guarde, em 12 de Fevereiro de 1729, Lisboa, 1729.

${ }^{45}$ Walter Rossa, Além da Baixa. Indícios de planeamento urbano na Lisboa setecentista, pp. 61-89. 
do Palácio e Convento das Necessidades já na década de 1740, erguido num dos extremos do terreno inicialmente escolhido para o novo paço e patriarcal e integrando "Giardino e Zappada per animali silvestre" 46 , como para ele fora previsto. Também em meados da mesma década $\mathrm{D}$. João $\mathrm{V}$ ordenou ao seu arquiteto residente da escola de Carlo Fontana, João Frederico Ludovice (1670-1752), a elaboração do projeto de uma nova patriarcal a ser erguida na Cotovia, no sítio que hoje é o Jardim do Príncipe Real e que acabaria por ser concretizado numa precária versão em madeira - a Patriarcal Queimada - logo a seguir ao Terramoto de $1755^{47}$.

Outro aspeto relevante é o conjunto de citações juvarrianas que têm vindo a ser aventadas por diversos autores em tramos da arquitetura da época. $\mathrm{Na}$ esmagadora maioria não são sequer atribuições, apenas a constatação de modos de detalhar que poderão ter sido induzidos a partir dos projetos áulicos e efémeros que Juvarra fez para $\mathrm{D}$. João $\mathrm{V}$, de que a documentação dá conta, mas de que nenhum restou. Entre eles avulta o Palácio e Convento de Mafra. Eu próprio fui dando conta disso em alguns dos textos já referenciados, mas foi Giuseppina Raggi quem recentemente apresentou resultados mais sólidos ${ }^{48}$, evidências que incluem a notícia da sua visita, críticas ásperas e desenhos para a obra que, de facto, de paralisada pouco depois passou por uma radical mudança de rumo e incremento. Não se trata de retirar a Ludovice o crédito da sua condução, mas sim de aumentar o pecúlio de ideias e modelos que teve de gerir e sintetizar para a concretização do conjunto que, pese embora a sua complexidade

${ }^{46} \mathrm{Ib}$, n. 38 .

${ }^{47}$ Id., "A imagem ribeirinha de Lisboa - alegoria de uma estética urbana barroca e instrumento de propaganda para o império"

${ }^{48}$ Giuseppina Raggi, "Filippo Juvarra in Portogallo: documenti inediti per i progetti di Lisbona e Mafra”. 
e diversidade, tem uma unidade evidente ${ }^{49}$. É ainda muito interessante constatar que todas as obras listadas no parágrafo anterior só tiveram lugar uma vez concluído o grosso da empreitada de Mafra.

Tal como o ourives-arquiteto João Frederico Ludovice, também o engenheiro militar Manuel da Maia (da mesma idade de Juvarra) terá participado no debate sobre a localização do paço e da patriarcal. Fora ele quem realizara o levantamento geral da cidade que serviu de base a todo o processo e quem ficou encarregue da condução do intempestivo início da obra quando Juvarra partiu de volta para Turim. Tenho vindo a chamar a atenção para a importância desta discreta colaboração, pelo facto de muitas das opções inscritas por Manuel da Maia enquanto estratega do Plano de $1758^{50}$ seguirem a nova visão instalada com a estadia de Juvarra em Lisboa no primeiro semestre de 1719 , desde logo a nova localização do Palácio Real em São João dos Bem Casados, ou seja, na atual zona das Amoreiras-Campo de Ourique. Todavia, não é tanto o posicionamento de um ou outro elemento urbano o que define o contributo de Juvarra para a paisagem urbana de Lisboa, mas a visão integrada e de salto de escala e ambição, patente desde o novo paradigma de plano global para uma cidade delimitada pela Linha Fundamental de Fortificação (concretizada pe-

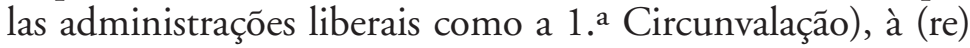

${ }^{49}$ Desde, pelo menos, Ayres de Carvalho, D. João V e a arte do seu tempo, Lisboa, ed. autor, 1962, 2 vols., até às referências basilares sobre o edifício mais recentes (José F. Pereira, Arquitectura e escultura de Mafra. Retórica da perfeição, Lisboa, Presença, 1994; António F. Pimentel, Arquitectura e poder. O real edifício de Mafra, Lisboa, Horizonte, 2002, 2. ${ }^{\text {a }}$ ed.), passando por Robert C. Smith, "The building of Mafra," Apollo, 134, 1973, pp. 359-367, estabeleceu-se um debate sobre a autoria do edifício que, a meu ver, nega o que é óbvio: num edifício daquela escala e diversidade, o que significa autoria? Quais são nisso os papeis da encomenda e da execução num contexto, como o português de então, de hegemonia procedimental da engenharia militar?

${ }^{50}$ É necessário ver-se o processo de planeamento intensamente desenvolvido para Lisboa após a catástrofe de 1 de novembro de 1755 num todo, ou seja, além do plano de reconstrução da Baixa. A propósito ver Walter Rossa, Além da Baixa. Indícios de planeamento urbano na Lisboa setecentista; id., "No 10 Plano". 
composição dos alçados e dimensionamento dos vãos. Lisboa tornava-se, finalmente, uma capital com uma paisagem urbana moderna, então mais para consumo do Império, e não a Roma do patriarcado metropolitano régio sobre os oceanos. Nisso tem ainda hoje papel crucial a recuperação da outra alternativa de 1679 à expansão do Paço da Ribeira, a duplicação em espelho da ala do paço transformando em praça o terreiro. Curiosamente parece que nunca terá sido considerada por D. João V, marquês de Fontes ou Juvarra.

A verdade é que apenas um impulso como a catástrofe de 1 de novembro de 1755, aliado à determinação e emergência do grande estadista Sebastião José de Carvalho e Melo (1699-1782), futuro marquês de Pombal, poderia ter feito despontar, com as adaptações necessárias a qualquer plano de renovação e ensanche de grande escala, as opções estratégicas básicas formuladas em 1719 e da qual acabou por ser veículo inteligente Manuel da Maia.

Ironicamente, a natureza em fúria, além de destruir todos os elementos de estudo e projeto que estariam no Paço da Ribeira no dia 1 de novembro de 1755, obliterou tudo quanto depois da partida de Juvarra se fez contra, ou melhor, adiando o seu plano, como as faustosas obras de renovação da Capela Real da Ribeira (por Ludovice), então erguida em Patriarcal, a Torre do Relógio (por António Canevari, mais um discípulo de Carlo Fontana), a nova Casa da Ópera (por Giovanni Carlo Sicino Galli Bibiena). Também e num outro extremo, as múltiplas operaçóes de alargamento de portas urbanas e ruas e o alinhamento de cérceas e edifícios, para não falar de chafarizes com alusões honoríficas a D. João $\mathrm{V}$ que, como Eduardo Lourenço limpidamente observou, "fu indubbiamente la maggiore vittima tra tutte quelle causate dal famoso terremoto di Lisbona del $1755^{\prime \prime}$. O que não é inteiramente verdade...

${ }^{51}$ Gabriele Borghini e Sandra Vasco Rocca (ed.), Giovanni V di Portogallo (17071750) e la cultura romana del suo tempo, p. 1. 


\section{DAMNATIO MEMORIE OU DIPLOMACIA?}

Ao fim de um semestre de atividade alucinante, Filippo Juvarra partiu de Lisboa para um pequeno périplo europeu que o levou a Londres e, então, de regresso ao Piemonte através da Holanda e França. Foi coberto de dinheiro e honrarias, incluindo a máxima distinção atribuída pela monarquia portuguesa, a Ordem Militar de Cristo com que já o seu mestre Carlo Fontana havia sido agraciado. "L'Architetto Jvarra [...] sendosi qui trovato quasi sempre indisposto per non conferirgli questo Clima, porta seco li dissegni delle consapute fabriche affine di perfettionarli in Italia, e poi qui rimetterli, e fra tanto l'orefice tedesco federico [Ludovice] haverà la direttione del principio di esse, come ha di quella di Mafra ${ }^{52}$. A 4 de julho "Há terminato finalmente il dissegno della noua chiesa Patriarcale, má quelli dell'altre fabriche ideate li finirà in Italia" ${ }^{33}$. Assumira também o compromisso de regressar para acompanhar a obra. Não sabemos porque não voltou, apenas que Vittorio Amedeo II o autorizou ${ }^{54}$. O mesmo sucede com os 500 artífices lombardos que, a pedido do arquiteto, D. João $\mathrm{V}$ mandou contratar para a execução da obra.

Todavia Juvarra voltaria à Península Ibérica com idênticas funções. Em 1735 D. Filipe V logrou contratá-lo para fazer o projeto de substituição do antigo Alcazar de Madrid, que havia sido destruído por um incêndio no ano anterior. A referência não podia ser mais clara, ainda que com um equívoco interessante: o rei ordenou ao seu ministro José $\mathrm{Pa}$ tiño que fizesse ir para Madrid o "architteto che fece la chiesa patriarcale di Portogallo, di cui non so il nome, ma solo

\footnotetext{
${ }^{52}$ HHSA, Portugal 6, 6-2, c. 61.

${ }^{53}$ HHSA, Portugal 6, 6-2, c. 63v.

${ }^{54}$ Leonarda Masini, Atti della Società Piemontese di Archeologia e di Belle Arte, 9, 2, 1920 , p. 283.
} 
che è siciliano, oggi si trova al servizio del re di Sardegna" 55 . Curiosamente também ali o siciliano considerou o lugar desadequado ao pretendido, sem capacidade transformadora da cidade, mas, ao invés do português, o monarca espanhol não comungou das suas opiniões tendo, aliás, sido parco no trato e nas condições de instalação e trabalho, do que o arquiteto não deixou de se queixar amargamente. A verdade é que o seu contributo efetivo acabou por ser diminuto, pois em 31 de janeiro de 1736, menos de um ano depois da sua chegada a Madrid, Juvarra morreu, alegadamente vítima de um inverno rigoroso, mas no curso do quadro depressivo a que o conduziram as más condiçôes de acolhimento ${ }^{56}$. Foi o seu assistente, Giovanni Battista Sacchetti, quem acabou por definir o projeto e a construção do que continua a ser a sede da monarquia espanhola. Como, em jeito de síntese, refere Beatriz Blasco Esquivias, "Con il refuto dei sovrani, Madrid perse una magnifica ocasione per trasformare la sua fisionomia urbana e la sua tradizionale gravitazione a ponente e dovette aspettare cent'anni perchè la Storia desse ragione a Juvarra sulle possibilità di espansione nella zona da lui indicata"s7.

Esse amargo episódio-epílogo da vida de Filippo Juvarra acabou por, paradoxalmente, dar lugar à sua consagração sob o epíteto "arquiteto das capitais" em duas exposições gémeas e respetivos catálogos, que tiveram lugar em Madrid em $1994^{58}$ e em Turim em 199559. Apesar de alguns dos respetivos textos o referirem de passagem, o caso de Lisboa não foi de forma alguma integrado, o que teria permitido o estabele-

55 Excerto cit. na p. 114 de Beatriz Blasco Esquivias, "Filippo Juvarra alla corte di Madrid: l'architettura nella capitale della Spagna attorno al 1736”, Vera Comoli Mandraci; Andreina Griseri (ed.), Filippo Juvarra. Architetto delle capitali da Torino a Madrid 1714-1736, Torino, Fabbri, 1995, pp.105-141.

${ }^{56} \mathrm{Ib}$.

${ }^{57}$ Ib., p. 131.

${ }^{58}$ António Bonet Correa; Beatriz Blasco Esquivias (ed.), Filippo Juvarra, de Mesina al Palacio Real de Madrid, Madrid, Electa, 1994.

${ }^{59}$ Filippo Juvarra. Architetto delle capitali da Torino a Madrid 1714-1736. 
cimento cabal da extraordinária dimensão urbanístico-estratégica do mestre siciliano, que em Lisboa veio a ter resultados com um impacto ainda hoje indelével. Permitiria ainda, e finalmente, desvelar essa espécie de ocultação, que só poderá ter surgido como forma de acautelar os impulsos regalistas de D. João V enquanto chefe supremo do Padroado português. 